\section{Interferon- $\gamma$-Freisetzungstest}

\author{
W. Stöcker \\ Euroimmun Medizinische Labordiagnostika AG, Lübeck, \\ Deutschland
}

Synonym(e) Gamma-Interferon-Freisetzungstest

Englischer Begriff interferon gamma-releasing test

Definition Der Interferon- $\gamma$-Freisetzungstest ist eine Exvivo-Testmethode zum Nachweis einer spezifischen Immunität. Er wird beispielsweise zur Diagnostik der Tuberkulose eingesetzt.

Beschreibung Hochspezifische Antigene aus Mycobacterium tuberculosis werden in vitro von antigenpräsentierenden Zellen aufgenommen. Sie stimulieren Gedächtniszellen, die im Rahmen einer früheren oder aktuellen spezifischen Infektion entstanden sind. Diese produzieren vermehrt verschiedene Botenstoffe, unter anderem $\gamma$-Interferon, das im Zellüberstand gemessen werden kann.

Zur Stimulation werden die Antigene ESAT-6 (,early secreted antigenic target"), CFP-10 (,,culture filtrate protein“) und $\mathrm{Tb} 7.7$ verwendet. Sie werden in der Frühphase der Tuberkulose-Infektion gebildet und weder von den Nichttuberkulose-Mykobakterien noch vom Impfstamm BCG (Bacille-Calmette-Guérin-Impfung) produziert. Frisches Vollblut des Patienten wird mit diesen Antigenen inkubiert und danach im Zellüberstand die Konzentration an $\gamma$-Interferon mittels Enzymimmuntest gemessen. In einem Parallelansatz (ohne spezifisches Antigen) gebildetes $\gamma$-Interferon muss von diesem Wert abgezogen werden. Alternativ kann man auch mit der sogenannten ELISPOT-Technik (Enzym-Linked-Immunospot-Assay) die Zahl der $\gamma$-Interferon-produzierenden Zellen bestimmen.

Einsatzgebiet Der Interferon- $\gamma$-Test wird bei Verdacht auf eine akute oder latente Tuberkulose $(\mathrm{Tb})$, zur Untersuchung von Kontaktpersonen, zum Screening von Risikogruppen oder Mitarbeitern im Gesundheitswesen sowie zum Ausschluss einer latenten Tuberkulose vor dem Beginn einer immunsuppressiven Therapie durchgeführt.

Der Interferon- $\gamma$-Test ist eine Alternative zum TuberkulinHauttest nach Mendel-Mantoux, der Kreuzreaktionen zu Mycobacterium bovis und verschiedenen Umwelt-Mykobakterien aufweist, nicht vorhersagbar nach einer BCG-Impfung reagiert oder unangenehme lokale Entzündungen im Testareal hervorrufen kann. Es muss aber mit Kreuzreaktionen zu M. kansasii, M. szulgai und M. marinum gerechnet werden.

\section{Literatur}

Detjen AK, Keil T, Roll S, Hauer B, Mauch H, Wahn U, Magdorf $\mathrm{K}$ (2007) Interferon-gamma release assays improve the diagnosis of tuberculosis and nontuberculous mycobacterial disease in children in a country with a low incidence of tuberculosis. Clin Infect Dis 45(3):322-328

Schablon A, Nienhaus A (2007) Interferon-gamma Release Assay zur Diagnose latenter Tuberkulose-Infektionen bei Routineuntersuchungen von Beschäftigten im Gesundheitswesen. Hyg Med 32(11): $430-436$ 